thiocyanate in acetic acid; while oxazolones with structures analogous to (II) yield thiohydantoins very readily under these conditions ${ }^{12}$.

The catalytic effect of sodium acetate on the racemization of acetyl-L-aspartic acid, noted by Barker, has also been observed with carbobenzyloxyL-aspartic acid ${ }^{13}$, the product again being a true anhydride.

A more complete account of these investigations will be published in the Australian Journal of Scientific Research, Series A.

\section{[Jan. 29.}

${ }^{1}$ Barker, C. C., Nature, 168, 908 (1951). 'Bergmann, M., Stern, F., and Witte, C., Liebigs Ann., 449, 227
(1926).

${ }^{3}$ Harington, C. R., and Overhoff, J., Biochem. J., 27, 338 (1933)

‘ Johnson, T. B., and Nicolet, B. H.. J. Amer. Chem. Soc., 38, 1973 (1911), and many later papers from this school. Schlack, P., and Kumpf, W., $Z$. physiol. Chem., 154, 125 (1926).

5 Johnson T. B., and Guest, H. H., Amer. Chem. J., 48, 103 (1912). Johnson, T. B., ibid., 49, 68 (1913). Johnson, T. B., and Nicolet, B. H., ibid., 197.

- Nicolet, B. H., J. Amer. Chem. Soc., 52, 1192 (1930).

${ }^{7}$ Thierfelder, H., Z. physiol. Chem., 114, 192 (1921).

Baker, W., and Jones, P. G., J. Chem. Soc., 1143 (1951).

- King, F. E., and Spensley, P. C., J. Chem. Soc., 3159 (1950).

${ }^{10}$ Karrer, P., and Keller, R., Helv. Chim. Acta, 28, 50 (1943).

${ }^{11}$ Waser, E., Mitt. Lebensm. Hyg., 20, 260 (1929).

${ }^{12}$ Johnson, T. B., and Scott, W. M., J.Amer. Chem. Soc., 35, 1136

(1913). "The Chemistry of Penicillin" (Clarke, H. T., Johnson, J. R., and Robinson, R., Editors), 286-7 (Princeton Univ. Press, Princeton, N.J., 1949).

19 Fruton, J. S., "Advances in Protein Chem.", 5, 41 (1949).

\section{CATIONIC POLYMERIZATION AND RELATED PROBLEMS}

$\mathrm{M}^{\mathrm{A}}$

ORE than eighty chemists from universities, research associations and industry were present at $a$ conference on cationic polymerization and related problems held at the University College of North Staffordshire during March 24-26. The members included visitors from the United States, France, Holland, the Irish Republic and Germany.

The first session (chairman, D. D. Eley) was devoted to those complexes which are related to cationic catalysis. D. D. Eley and P. J. King (University of Bristol) showed that benzene and aluminium bromide form a weak 1:1 complex. In the presence of hydrogen bromide two phases are formed, the upper one weakly, the lower one (red oil) strongly conducting. The composition of the red oil approximates to $\mathrm{Al}_{2} \mathrm{Br}_{6} \cdot \mathrm{HBr} \cdot 6 \mathrm{C}_{6} \mathrm{H}_{6} \cdot \mathrm{G}$. Baddeley and D. Voss (Manchester College of Technology) showed that a third component such as hydrogen bromide is necessary for the formation of complexes between aluminium bromide and aromatics. They have found the rate of isomerization of $p$-xylene to $m$-xylene by aluminium bromide to be proportional to the concentration of hydrogen bromide. No toluene or tri-methyl benzenes are formed, showing that the isomerization is an intra-molecular process. F. Fairbrother (University of Manchester) said that vapourpressure studies have shown that pentene- 2 does not form a complex with aluminium bromide. N. M. Cullinane (University College, Cardiff) reported the isolation of the complexes $\mathrm{C}_{6} \mathrm{H}_{6} .3 \mathrm{TiCl}_{4}$ and $\mathrm{C}_{6}\left(\mathrm{CH}_{3}\right)_{6} .3 \mathrm{TiCl}_{4}$. D. D. Eley and $\mathrm{H}$. Watts reported the isolation as colourless crystals of $\mathrm{C}_{5} \mathrm{H}_{5} \mathrm{~N}$. Al $X_{3}$ and $\left(\mathrm{CH}_{3}\right)_{3} \mathrm{~N} . \mathrm{Al} X_{3}$, where $X$ is chlorine, bromine or iodine, and of $\left(\mathrm{C}_{2} \mathrm{H}_{5}\right)_{3} \mathrm{~N} \cdot \mathrm{AlCl}_{3}$. The melting points of the complexes depend mainly on the nature of the base. The clissociation energies of the pyridine-Al $X_{3}$ com- plexes for $X=\mathrm{Cl}, \mathrm{Br}$ and $\mathrm{I}$ are respectively 32,32 and $70 \mathrm{kcal} . / \mathrm{mol}$. T. R. E. Devlin and D. C. Pepper ('Trinity College, Dublin) reported the isolation of the complexes $\mathrm{SnCl}_{4} .3 \mathrm{H}_{2} \mathrm{O}, .3 \mathrm{EtOH}, .2 \mathrm{EtOH}, .2 \mathrm{Me}_{3} \mathrm{CO}$ and $.2 \mathrm{Et}_{2} \mathrm{O}$. The last three of these will initiate the polymerization of styrene in dichlorethane or nitrobenzene, but not in benzene. A mono-hydrate of stannic chloride could not be isolated. H. A. Skinner (University of Manchester) examined the energetics of co-ordinate link formation, emphasizing the parts played by the electron affinity of the acceptor and the ionization potential of the donor in relation to the stability of the complex. Some complexes of boron trifluoride to oxygen- and nitrogen-containing donors were used for illustrating the potentialities of the scheme proposed. J. Chatt (Imperial Chemical Industries, Ltd.) discussed the complexes of olefins with platinum and contrasted them with the silverolefin complexes, which were then discussed in detail by G. Salomon (Rubber Stichting, Delft). The discussion centred mainly around the nature of the various types of linkage involved in these complexes.

The second and third sessions (chairman, D. C. Pepper) were devoted to the polymerization of arylenes. D. C. Pepper, working with styrene-stannic chloride-dichlorethane, found that rigorous drying increases the rate of reaction. A. Somerfield (Dublin), using stannic bromide in the same system in place of stannic chloride, found that the addition of hydrogen bromide increases the rate, reduces the molecular weight, and removes the induction period. With both catalysts the rate is proportional to [catalyst] $\times$ [styrene] ${ }^{2}$ for styrene concentrations up to $1.74 \mathrm{~mol}$./1. G. Williams and K. Heald (Royal Holloway College, London) found that the polymerization of styrene by stannic chloride in carbon tetrachloride is temporarily but completely inhibited by hydrogen chloride, due to the formation of 1-phenyl ethyl chloride. F. S. Dainton et al. (University of Leeds) reported that, in the system styrene-stannic chloride-carbon tetrachloride, water is not a co-catalyst. The rate is proportional to the catalyst concentration, and with respect to styrene the reaction is almost third-order in the range 0-1 $M$ and second-order in the range 1-4 $M$. For $\alpha$-methyl styrene-stannic chlorideethyl chloride they found that water is a co-catalyst and that at constant water concentration the rate $=k_{1}$ [stannic chloride $]^{1.5} \times$ [monomer] ${ }^{y}$, where $y$ varies from 1 at low monomer concentration to higher values at high monomer concentration. The degree of polymerization is $2+k_{2}[m]_{0}$, where $[m]_{0}$ is the initial monomer concentration. Prof. Dainton showed that, if one assumes that the propagation-rate constant depends on the chain-length, the variable order of reaction with respect to the monomer can be explained. P. H. Plesch (University College of North Staffordshire) showed that the polymerization of styrene by titanium tetrachloride in dichlorethane is greatly accelerated by traces of water, but will proceed in its absence. He has found in addition, by infra-red analysis of end-groups, that dichlorethane, ethyl bromide, isopropyl bromide and tert.-butyl bromide probably act as co-catalysts and that, when styrene is polymerized by titanium tetrachloride in toluene with trichloracetic acid as co-catalyst, the low polymer obtained contains tolyl end-groups. He has also shown that the dielectric constant of the solvent is not the only, or even the most important, property of the solvent which influences the rate of polymerization. D. O. Jordan and A. R. Mathieson (University of Nottingham) reported on the polymer- 
ization of styrene in carbon tetrachloride and of $\alpha$-methyl styrene in carbon tetrachloride and ethyl chloride by aluminium chloride. For these systems they have found that the rate is proportional to the first power of the catalyst and of the monomer concentrations, that neither water nor hydrogen chloride acts as co-catalyst, that the catalyst becomes inactivated, and that solvent transfer occurs. D. Clark (University of Birmingham) reported that the polymerization of styrene by boron trifluoride in carbon tetrachloride will not proceed in the absence of a co-catalyst and that it is very sensitive to traces of water, which is a co-catalyst. It was stated by R. O. Colclough (University of Leeds) that, when styrene is polymerized in nitrobenzene or cyclohexane by antimony pentachloride containing radioactive antimony, the catalyst does not remain attached to the polymer, even when this is purified under anhydrous conditions. Most of those engaged on this work were agreed that the polystyrenes and poly- $\alpha$ methyl styrenes contain few, if any, double bonds and that the end-groups are probably substituted indanes. D. S. Brackman and P. H. Plesch said that, contrary to earlier work by others, they have been unable to isomerize cis-stilbene by boron trifluoride or titanium tetrachloride. In the absence of a co-catalyst there is no reaction; in the presence of one, both cis-and trans-stilbene polymerize. For the system trans-stilbene-titanium tetrachloride-trichloracetic acid, the polymerization is zero-order in monomer up to high degrees of conversion, but these constant rates are, for a series of experiments, proportional to [titanium tetrachloride] [trichloracetic acid] [stilbene] ${ }^{2}$. C. G. Overberger (Brooklyn Polytechnic) gave an account of the co-polymerization of various substituted styrenes by stannic chloride and showed that the monomer reactivity ratios follow, with few exceptions, the Hammett sigma constants. The monomer reactivity ratios are found to be almost independent of the temperature over the range $-20^{\circ}$ to $+30^{\circ} \mathrm{C}$., and of the dielectric constant of the solvent over the range $2 \cdot 2-29 \cdot 7$, nor are they affected by the catalyst concentration or the presence of small quantities of water.

The fourth session of the conference was devoted to alkenes. K. E. Russell (University of Manchester) reported that, in the polymerization of isobutene in ethyl chloride by stannic chloride at low temperatures, water, nitroparaffins and halo-acetic acids are co-catalysts, but nitrobenzene is not. The rate is proportional to [monomer] [water] and the molecular weight to [monomer]/[water]. M. St. C. Flett (Imperial Chemical Industries, Ltd.) and P. H. Plesch demonstrated from infra-red spectra that, when isobutene is polymerized in hexane by titanium tetrachloride with trichloracetic acid as co-catalyst, the predominant end-group is methylene, but that there are also smaller numbers of tri-substituted double bonds and of trichloro-acetate end-groups. A. Wassermann (University College, London) discussed the polymerization of cyclo-pentadiene by trichloracetic acid to a highly coloured polyene. I'he rate in carbon tetrachloride solution is proportional to [monomer] [trichloracetic acid] ${ }^{2}$. T'his polymer is a ready proton-acceptor and differs from that formed under the influence of metal halides. Possible structures for these polymers were discussed at some length. D. D. Eley and J. Saunders reported that the rate of polymerization of alkyl vinyl ethers by iodine is proportional to [monomer] $\left[\mathrm{I}_{2}\right]^{2}$, but that at high monomer concentration the rate passes through a maximum. The rate-constant at low monomer concentrations, and the maximum rate as well as the monomer concentration at which it is attained, are functions of the side-chain. G. W. A. Rijnders and C. G. A. Schuit (K. Shell Lab., Amsterdam) discussed polymerization and cracking on silica-alumina catalysts and directed attention to the dehydrogenation reactions which may accompany cationic polymerizations. L. Wall (National Bureau of Standards, Washington, D.C.) and C. G. Overberger presented three papers by C. M. Fontana et al. (Socony-Vacuum Laboratories, New Jersey). It was shown that in the polymerization of propene or butene-1 by aluminium bromide at low temperatures, a high concentration of co-catalyst such as hydrogen bromide is required to give high molecular weights, whereas isobutene under these conditions gives polymers of low molecular weight. The distribution of molecular weight of polypropenes and other evidence indicate that the transfer of tertiary hydride ions plays a dominant part in these reactions.

The discussions in the second, third and fourth sessions of the conference were mainly concerned with questions of technique, the reasons why cocatalysts are required in some systems but not in others, the effect of the dielectric constant of the medium and the relation between cationic polymerization and conventional Friedel-Crafts reactions. Prof. Dainton gave a final summing-up of the conference. The full proceedings of the conference will be published in book form. P. H. Plesor

\section{TRANSPARENT CONDUCTING FILMS ON GLASS}

$\mathrm{B}^{\mathrm{a}}$ ÄDEKER in $1907^{2}$ made some of the earliest observations on non-metallic films, obtained by suitable after-treatment of sputtered metal films. $\mathrm{He}$ observed that some, particularly certain oxide films, had appreciable electrical conductivity. After a comparative lull in interest, modern evaporation techniques provided a new stimulus for the study of non-metal films. Attention was then directed first to their optical properties. Rather later, research on semi-conductors and photocells aroused increasing interest in the electrical properties of the films. It is curious, perhaps, that not many investigators have hitherto studied both the optical and electrical properties and attempted to relate them to each other. Recently, however, the importance of their inter-relation has been emphasized by commercial applications in which both good transparency and the possibility of dissipating considerable electrical power in the films are prerequisites. The American so-called NESA film, used for electrically heated windscreens and windows, is a case in point.

In the Light Division of the National Physical Laboratory a study of this field started in 1947, in connexion with research on the selenium rectifier photocell. In this cell, the upper layer or film must of necessity be a fairly good conductor; but it must also be as transparent as possible if the sensitivity of the cell is not to be too much reduced by loss of light in transmission through it. In this study, Bädeker's experiments were repeated on a wider range of metals. His results-for example, on oxidized 